\title{
Spatial Differentiation of Small Holder Farmers' Vulnerability to Climate Change in the Kyoga Plains of Uganda
}

\author{
Oketcho Chombo $^{1}$, Shuaib Lwasa ${ }^{1}$, Tenywa Moses Makooma ${ }^{2 *}$ \\ ${ }^{1}$ Department of Geography, Geoinformatics and Climate Sciences, Makerere University, Kampala, Uganda \\ ${ }^{2}$ Department of Agricultural Production, Makerere University, Kampala, Uganda \\ Email: *ojosephat@gmail.com
}

How to cite this paper: Chombo, O., Lwasa, S. and Makooma, T.M. (2018) Spatial Differentiation of Small Holder Farmers' Vulnerability to Climate Change in the Kyoga Plains of Uganda. American Journal of Climate Change, 7, 624-648. https://doi.org/10.4236/ajcc.2018.74039

Received: September 14, 2018

Accepted: December 11, 2018

Published: December 14, 2018

Copyright (c) 2018 by authors and Scientific Research Publishing Inc. This work is licensed under the Creative Commons Attribution International License (CC BY 4.0).

http://creativecommons.org/licenses/by/4.0/ (c) (i) Open Access

\begin{abstract}
The paper assessed the variation in the level of vulnerability to climate change among small holder farmers in the Kyoga plains of Uganda. It was hypothesized that there is no spatial variation in the level of vulnerability to climate change among the small holder farmers of different socioeconomic characteristics in the Kyoga plains. It improves the understanding of the different dimensions of vulnerability. This can help to design practical policies and intervention strategies that are specific to the communities' spatial strata to reduce development imbalances and empower the most vulnerable small holder farmers. The conceptual framework is based on the three elements of vulnerability that is, exposure, sensitivity and adaptive capacity. The cross-sectional survey research design was used to collect both quantitative and qualitative data. Household data were acquired by using a structured questionnaire supported by focussed group discussions while meteorological data were collected using data base review. The study was done in the Kyoga plains agro ecological zone of Uganda comprising of several districts out of which Tororo and Pallisa were picked. Indicators for the components of vulnerability (Exposure, Sensitivity and Adaptive Capacity) were selected by Principle Component Analysis (PCA) and Vulnerability Indices constructed at household level then aggregated at sub county level for correlation using ANOVA. Inter sub county vulnerability index correlation revealed a spatial variation in the level of vulnerability between the different sub counties with Kasodo Sub County in Pallisa being the most vulnerable and Rubongi in Tororo being the least vulnerable. Policy measures and development efforts should therefore focus on place specific strategies of adapting to climate change rather nationwide or region wide strategies. There is also need to refocus policy to nonfarm activities which are less susceptible to climate change and enhance farmers' income.
\end{abstract}




\section{Keywords}

Exposure, Sensitivity, Adaptive Capacity, Vulnerability indices, Principal Component Analysis

\section{Introduction}

It has been noted that in Uganda, some climate change induced outcomes have been as integral components of the overall constraints to agricultural productivity for instance up to $34 \%$ of crop damage in the country is caused by climate induced stimuli [1] such as rainfall shortage, crop diseases and insect damage [2]. Whereas this is accurate, the scale of scoping is macro hence we cannot be able to appreciate the area specific climate change impacts.

It has further been noted that Uganda is vulnerable to climate change as most of its agriculture is rain fed yet agriculture is the backbone of the economy. Any slight variation in climate may therefore be reflected in the productivity of agricultural systems across the country and pronounced variability may result in adverse physical, environmental and socio-economic impacts. Rainfall across the country is currently unreliable and highly variable in terms of its onset, cessation, amount and distribution, leading to either low crop yields or total crop failure [2] [3] [4].

Studies have been done on vulnerability and climate change among small holder farmers in Africa and Uganda in particular for instance; [4] [5]. These studies deal with vulnerability to climate change among small holder farmers but they are either exclusively biophysical [4] [6] or socioeconomic [5] [7] [8], in their approach to vulnerability assessment with attention given on crop yields, animal production or the socioeconomic characteristics of the farmers. However, it is increasingly being recognized that vulnerability cannot be fully understood by exclusively assessing either biophysical or socioeconomic conditions [9] [10], hence the need for more comprehensive and holistic approaches to the assessment of vulnerability that integrates both socioeconomic and biophysical aspects of vulnerability to climate change among small holder farmers.

The current study explores both the biophysical and socioeconomic conditions associated with vulnerability to climate change among small holder farmers in the Kyoga plains of Uganda. Whereas it is known that farmers in the Kyoga plains are generally vulnerable to climate change, there seems to be a knowledge gap regarding the spatial dimension of the vulnerability to climate change in relation to the socio-economic characteristics of small holder farmers. The study therefore examines the spatial differentiation in the extent to which the level of vulnerability to climate change varies among small holder farmers of different socioeconomic characteristics in the Kyoga plains of Uganda.

The main objective of the paper is to assess the spatial variation in the level of vulnerability to climate change risks (drought and floods) among small holder 
farmers of different socioeconomic characteristics in the Kyoga plains of Uganda. It is hypothesized that there is no spatial variation in the level of vulnerability to climate change among the small holder farmers of different socioeconomic characteristics in the different parts of the Kyoga plains of Uganda. The paper generates scientific evidence to show the extent to which the level of vulnerability to climate change vary among small holder farmers of different socioeconomic characteristics in the different parts of the Kyoga plains of Uganda. This highlights the spatial dimensions of the impacts of climate change in communities and ultimately improves the understanding of the different dimensions of vulnerability which different stake holders in government, private sector, civil society and the international community can use to design practical policies and intervention strategies that are specific to the communities' spatial strata rather than a situation where by climate change impacts are assessed on the general community as if it is spatially homogenous. Such analysis is also essential for policy decision making to reduce development imbalances and empower the most vulnerable small holder farmers.

\section{Materials and Methods}

\subsection{Profile of the Study Area}

The study was done in the Kyoga plains agro ecological zone of Uganda which is one the ten agro ecological zones in the country according to the National Agricultural Research Organization (NARO) classification [11]. The zone comprises the districts of Kayunga, Kamuli, Iganga, Bugiri, Busia, Tororo, Manafwa, Mbale, Pallisa, Kumi, Soroti, Kaberamaido, Lira and Apac (Figure 1).

The area is characterized by the following climatic features:

The average rainfall is $1215-1238 \mathrm{~mm}$, two rainfall seasons in the southern part of the zone (Tororo) (Figure 1), that is, March-May and August-November and one dry season, between December to February. Evaporation exceeds rainfall during the dry months while during the rainy season; rainfall is greater or equal to evaporation.

In the northern part of the agro-ecological zone (Pallisa) (Figure 1), there is one rainy season, that is, March to November and one dry season, December to March. Evaporation exceeds rainfall during dry months and rainfall is greater or equal to evaporation during dry months.

The temperature ranges between $24^{\circ} \mathrm{C}-36^{\circ} \mathrm{C}$. The altitude ranges from $914-$ 1800 metres above sea level. The land is mainly flat and swampy and the soils range from low to moderate productivity [12].

The Kyoga plain was chosen because it is an important focal area for Uganda given its importance in the Nile basin. The area has important resources for production for example fresh water, vegetation, soil, to mention but a few and yet there are significant differences in human welfare indicators such as health, population, poverty, food security and others [13]. The Kyoga plains have a fast-growing population with a growth rate of $4 \%-6 \%$ with the poverty and 


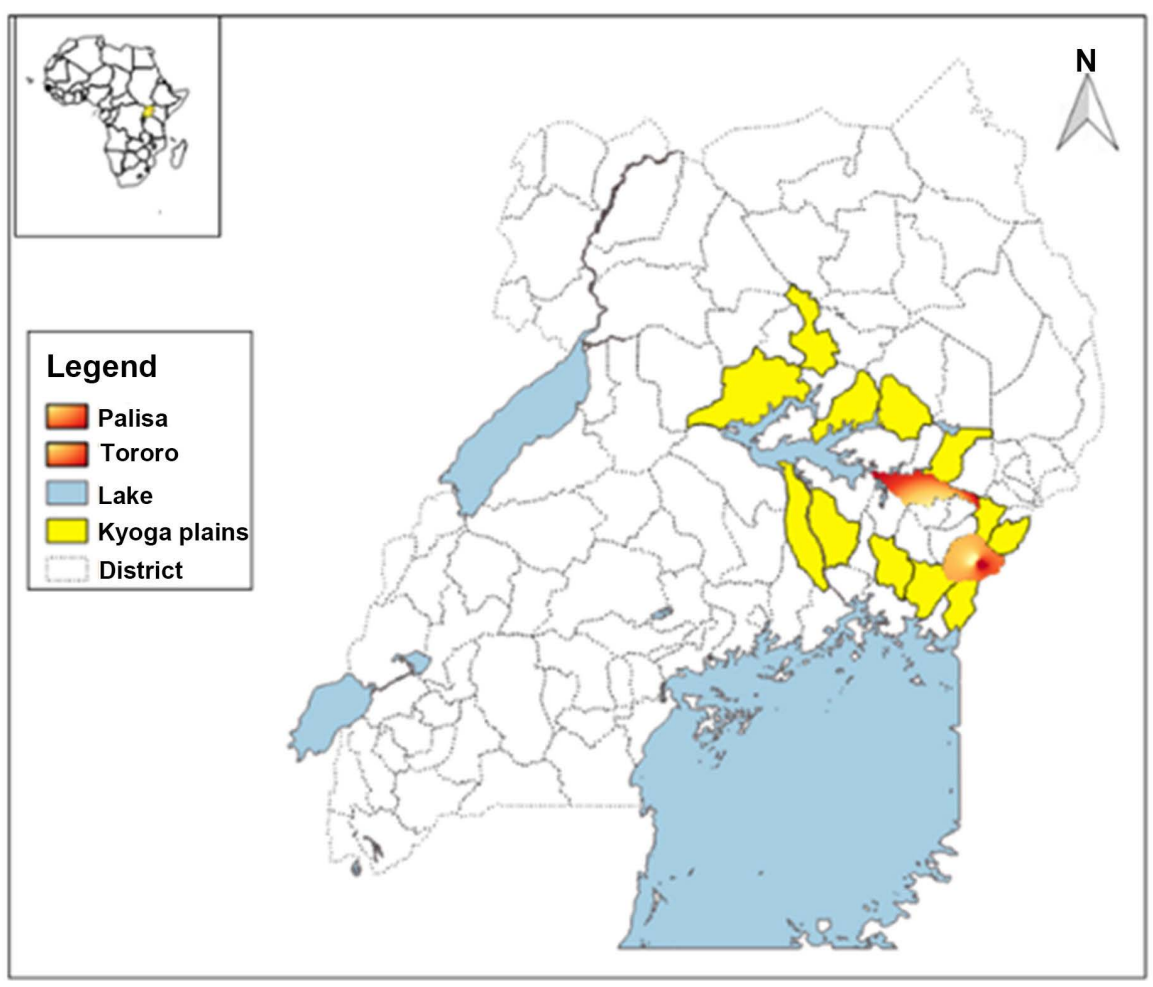

Figure 1. Map showing the study area.

food security situation worse than the national average. Northern Uganda (Lira, Apac, among others), which form part of the Kyoga plains, is the poorest region in the country, with a poverty level of $75.8 \%$ of the population.

One district was chosen from the northern sub zone (Pallisa) and one from the southern sub zone (Tororo), respectively. This was done purposively because these two districts are particularly vulnerable to climate change and given their proximity to other districts, it is hoped that results from these will reflect the conditions in the others.

Tororo district has a total land area of 1193.8 square kilometres and is estimated to have 103,585 households with a total population of 517,080 , out of which 250,830 are males and 266,250 are female, giving a sex ratio of 94.2. In addition, Tororo has a total of 22 sub counties including the two divisions of Tororo Municipality. The district has over the years witnessed environmental degradation manifested in deforestation, poor garbage management and wetland encroachment. Most of the shallow wetlands have been drained for rice growing.

On the other hand, Pallisa district has 63.4 square kilometres, 66,668 households with a total population of 386,890 people, 186,125 of whom are male and 198,765 are female and a sex ratio of 94.6. In addition, Pallisa has a total of 19 sub counties including Pallisa Town Council. Pallisa is one of the poorest districts in eastern Uganda located in the plains of the Lake Kyoga system. The district is one of the poverty hotspots in the country and region with an index of $63 \%$ [14]. The district is also home to the extensive wetland of Mpologoma river with numerous lakes that form part of the Kyoga system. The area is in a natural 
sink with lakes, large ponds and permanent wetlands, the nearest and biggest being Nakuwa that is also a Ramsar Site [14]. The area is also characterized by low-lying grasslands with soil types that are of medium to low productivity [12].

\subsection{Research Design and Data Collection Procedure}

The cross-sectional research design was used in the study. Structured questionnaires and focus group discussions were used to elicit data from the small holder farmers on their level of exposure, sensitivity and adaptive capacity to climate change, from which vulnerability indices were computed.

A reconnaissance was initially done with a view of establishing the main climate risks that are common in the area and the livelihood issues that could constitute the indicators of adaptive capacity and sensitivity. This was to validate the indicators that had been identified from literature. The respondents were consulted on the major climate risks that occur in their community, how these affect their livelihoods and how they deal with these impacts. The outcome of the reconnaissance helped to strengthen the survey tool.

Following the reconnaissance, a survey was conducted with a total of three hundred and eighty-four respondents, chosen across the two districts of study. Two sub counties were chosen per district and from each of these, two parishes were chosen then three villages were chosen from each parish. Sixteen respondents were then chosen from each village basing on the list of residents from the LC one chairperson. This was first stratified to male and female headed households and from each substratum, an appropriate number randomly picked to make the sixteen. These were then interviewed using a semi structured questionnaire with the help of five local interviewers. These interviewers were able to speak the main languages used in Palisa and Tororo districts.

Prior to conducting the survey, the interviewers were trained in data collection methods of surveys and use of Global Positioning System (GPS) for coordinate readings of household locations. A part from this, observation and focused group discussions were held thereafter to generate views on community-wide climate risks experienced and livelihood issues that constituted indicators of vulnerability. For all the surveyed households GPS readings for location were taken.

This paper also makes use of raw monthly minimum and maximum temperature and monthly precipitation data obtained from the Uganda National Meteorological Authority (UNMA) in Kampala Uganda for 30 years (1984-2014), the period recommended by the World Meteorological Organisation (WMO) [15]. Temperature and precipitation data were obtained for four meteorological stations distributed across the agro-ecological zone namely, Tororo, Soroti, Lira and Jinja. Data from more stations from within the region like Serere, Kamuli and Mbale were anticipated but these were reported to be having so much gaps hence the four were relied upon since it is all that was available. The temperature and precipitation at the household level was interpolated for each year from the weather stations using the latitude-longitude-altitude information of each 
household by ordinary kriging method in ArcGIS 10.4 .

\subsection{Conceptual Framework of Vulnerability}

Vulnerability is the degree to which geophysical, biological and socio-economic systems are susceptible to and unable to cope with adverse impacts of climate change, including climate variability and extremes [16]. According to [17], three main models for conceptualizing and assessing vulnerability can be distinguished. The first is the risk-hazard framework (biophysical vulnerability assessment), which is characteristic of the technical literature on risk and disaster management. It conceptualizes vulnerability as the dose-response relationship between an exogenous hazard to a system and its adverse effects. This notion of vulnerability corresponds most closely to "sensitivity" in IPCC terminology.

The second is the social constructivist framework (social vulnerability assessment), which prevails in political economy and human geography. It regards vulnerability as a priori condition of a household or a community that is determined by socio-economic and political factors. Vulnerability according to this view is seen as the socioeconomic causes of differential sensitivity and exposure.

The third is integrated framework (both bio physical and social vulnerability assessment), which is related to the IPCC definition of vulnerability (to climate change), that is, the degree to which a system is susceptible to, or unable to cope with adverse effects of climate change, including climate variability and extremes [18]. Vulnerability is a function of the character, magnitude, and rate of climate variation to which a system is exposed, its sensitivity, and its adaptive capacity. Vulnerability, according to this definition, is an integrated measure of the expected magnitude of adverse effects to a system caused by a given level of certain external stressors.

Vulnerability, according to this school, includes an external dimension, which is represented here by the "exposure" of a system to climate variations, as well as an internal dimension, which comprises its "sensitivity" and its "adaptive capacity" to these stressors [19]. This study uses the integrated framework approach of vulnerability assessment, in line with the IPCC 2001 frame work [18].

According to [10], two approaches are generally used in literature to assess vulnerability: vulnerability variable assessment and the indicator approach. The vulnerability variable assessment approach is an econometric approach that measures the welfare loss for selected variables of concern for example house hold consumption, agricultural yield, among others, in relation to specific sets of stressors, such as climate change. Several generic vulnerability metrics have been proposed in economic and agricultural studies. While these metrics can provide an indication of the vulnerability of a given place, they are not sufficient to fully capture all the three dimensions of vulnerability [20].

On the other hand, the indicator approach uses a specific set or combination of indicators (proxy indicators) and measures vulnerability by computing indices, averages or weighted averages for those selected variables or indicators. This approach can be applied at any scale (household, county/district, or national level). 
The major limitation of the approach is that the application of indices is limited by subjectivity in the selection of variables. However, the indicator approach is valuable for monitoring trends and exploring conceptual frameworks. The composite indices can capture the multi-dimensionality of vulnerability in a comprehensible form. Vulnerability indicators are needed for practical decision-making processes, to provide policy makers with appropriate information about where the most vulnerable individuals are located.

This study assessed the spatial variation in the level of vulnerability of small holder farmers to climate change and therefore adopted the indicator approach in line with the integrated vulnerability conceptualisation approach [17] highlighted above, which provides a multi-dimensional or integrated outlook of vulnerability and information about where the most vulnerable individuals are located.

As noted by [18] vulnerability comprises of three elements, that is, exposure, sensitivity and adaptive capacity, which are conceptualised below.

Exposure is the nature and degree to which a system is exposed to significant climatic variations [21]. It refers to the stress that impacts a system; the extent to which a system is exposed to the climate hazard [9]. The indicators of exposure here include historical changes in climate variables (temperature and rainfall) and the frequency of occurrence of extreme climatic events (drought and floods).

Sensitivity is the degree to which a system is modified or affected by an internal or external disturbance or set of disturbances [21]. Sensitivity represents the system's condition that can reduce or worsen the impact. Frequency of disease out breaks, income structure and loss of properties (viz livestock, house hold property and crop) due to climate related disasters over the last thirty years represent the sensitivity for the purpose of this study.

Adaptive capacity is the ability of a system to adjust to climate change including climate variability and extremes, to moderate the potential damage from it, to take advantage of its opportunities, or to cope with its consequences [9].

\subsection{Choice of Indicators and Calculation Vulnerability Indices/Data Analysis}

Following the definition of vulnerability given by the IPCC 2001 frame work [18], vulnerability in this study is taken to be a function of exposure, sensitivity, and adaptive capacity. Exposure is the nature and degree to which a system is exposed to significant climatic variations. Sensitivity is the degree to which a system is affected, either adversely or beneficially by climate-related stimuli. Adaptive capacity is the ability of a system to adjust to climate change including climate variability and extremes, to moderate the potential damage from it, to take advantage of its opportunities, or to cope with its consequences. Selection of indicators for adaptive capacity is based on the British Department for Foreign Development (DFID) sustainable livelihoods framework, whereby adaptive capacity is taken to be a function of asset possession by the households [13] [21]. 


\subsubsection{Exposure}

For this study, historical changes in climate variables and occurrence of extreme climatic events constitute the indicators of exposure (Table 1). Rate of change in average annual maximum temperature, average annual minimum temperature and average annual precipitation for the time period of 1984-2014 represent the historical climate changes. The temperature and precipitation for individual household were interpolated for each year from the station level data (four temperature stations and four precipitation stations) using the latitude, longitude, and altitude information of the stations and the households by ordinary kriging method in Arc GIS 10.4. The coefficient of the trends of climate variables was calculated separately for each household. Floods and droughts are the most commonly occurring natural disasters in the study area. Number of occurrences of these extreme events for the last ten years was obtained for each household from the household survey. It was hypothesized that the higher the rate of change of the climate variables and higher the frequency of extreme climate events, the higher would be the exposure of the households to climate change and extremes.

\subsubsection{Sensitivity}

Sensitivity is the degree to which a system is modified or affected by an internal or external disturbance or set of disturbances [21]. Accordingly, indicators of sensitivity in this study include; frequency of disease out breaks, fatalities, that is, death of family members due to flood or drought and loss of properties (viz livestock, house hold property and crops) due to climate related disasters over the last ten years (Table 2). It was hypothesized that higher rates of change in the past climatic hazards would increase the frequency of disease out breaks hence the sensitivity of the households to such events. The other indicator is fatality of members of the household. It was hypothesized that the higher the frequency of extreme climate events like floods and drought, the higher would be the rate of death of family members as a result of these events hence higher sensitivity of the community to climate change. In the same vain, a higher rate of change in past climatic events would lead to more damage to property namely, livestock, household property and crops hence more sensitivity.

\subsubsection{Adaptive Capacity}

Adaptive capacity is indicated by the five types of livelihood assets viz. physical, human, natural, financial, and social indicators as explained and hypothesized here (Table 3).

Physical assets: type of house, ownership of devices to access information (mobile phone, radio and television) and walking distance to the nearest motor road. Possession of better-quality house would improve the capacity to with stand the risks from extreme climate events. Type of house was indicated by a value of $1-3,3$ indicated the most durable type of house (see Table 3). Ownership of mobile phone, radio and television would increase the adaptive capacity through access to weather related information which would enable households 
Table 1. Indicators of exposure across the sub counties.

\begin{tabular}{|c|c|c|c|c|c|c|c|c|}
\hline Indicator & Description of Indicator & Weight & Aggregate & Kisoko & Rubongi & Apopong & Kasodo & P-value \\
\hline & & & $\mathrm{n}=384$ & $\mathrm{n}=98$ & $\mathrm{n}=98$ & $\mathrm{n}=98$ & $\mathrm{n}=98$ & \\
\hline Minimum Temp & $\begin{array}{l}\text { Rate of change in average } \\
\text { annual minimum temperature }\end{array}$ & -0.97 & -0.81 & $-7.5(0.4)$ & $-8.7(0.5)$ & $-10.0(1.1)$ & $-6.1(0.5)$ & $0^{* * *}$ \\
\hline Maximum temp & $\begin{array}{l}\text { Rate of change in average } \\
\text { annual maximum temperature }\end{array}$ & 0.99 & 7.2 & $6.5(0.4)$ & $7.8(0.5)$ & $8.7(0.8)$ & $5.8(0.4)$ & $0^{* * *}$ \\
\hline Rainfall & $\begin{array}{l}\text { Rate of change in average } \\
\text { annual rainfall }\end{array}$ & 0.86 & 4.1 & $3.6(0.3)$ & $4.8(0.5)$ & $4.5(0.1)$ & $3.8(0.1)$ & $0^{* * *}$ \\
\hline $\begin{array}{l}\text { Extreme climate } \\
\text { events }\end{array}$ & Number of extreme climate events & 0.97 & 5.4 & $4.2(2.9)$ & $6.8(4.4$ & $3.5(3.1)$ & $7.3(5.8)$ & $0^{* * *}$ \\
\hline
\end{tabular}

Source: Interpolated raw data from UNMA 2017/18; Note: Figures in parenthesis indicate standard deviation; ${ }^{* *}$ indicate significant at $1 \%$ level of significance.

Table 2. Sensitivity indicators across the sub counties.

\begin{tabular}{|c|c|c|c|c|c|c|c|c|}
\hline Indicator & $\begin{array}{l}\text { Description of } \\
\text { indicator }\end{array}$ & Weight & Aggregate & Kisoko & Rubongi & Apopong & Kasodo & P-value \\
\hline & & & $\mathrm{n}=384$ & $\mathrm{n}=98$ & $\mathrm{n}=98$ & $\mathrm{n}=98$ & $\mathrm{n}=98$ & \\
\hline Climate events & Number & 0.722 & 1.15 & $1.1(0.3)$ & $1.2(0.5)$ & $1.1(0.4)$ & $1.2(0.5)$ & 0.239 \\
\hline House hold property lost & Uganda shillings & 0.864 & 6015563 & $\begin{array}{c}411,666.7 \\
(515,992.5)\end{array}$ & $\begin{array}{c}854,791.7 \\
(2,217,578.7)\end{array}$ & $\begin{array}{c}1,050,208.31 \\
(48428.7)\end{array}$ & $\begin{array}{c}89,583.3 \\
(1,548,428.7)\end{array}$ & $0^{* * *}$ \\
\hline Livestock lost & Number & 0.502 & 3.45 & $4.4(4.6)$ & $3.3(3.8)$ & $2.6(3.6)$ & $3.5(3.4)$ & 0.19 \\
\hline Crops lost & Uganda shillings & 0.898 & $701,322.3$ & $\begin{array}{c}435,056.2 \\
(461,767.9)\end{array}$ & $\begin{array}{c}537,034.9 \\
(707,909.3)\end{array}$ & $\begin{array}{l}1,087,849.5 \\
(282,132.9)\end{array}$ & $7,453,485,348)$ & $0^{* * *}$ \\
\hline Other Losses & Number & 0.548 & 0.7 & $0.8(0.4)$ & $0.8(0.4)$ & $0.4(0.5)$ & $0.8(0.4)$ & $0^{* * *}$ \\
\hline Outbreak of diseases & Number & -0.758 & 1.85 & $1.4(0.8)$ & $1.8(0.8)$ & $2.8(1.3)$ & $1.4(1.0)$ & $0^{* * *}$ \\
\hline Victims of diseases & Number & 0.535 & 2.725 & $2.5(2.1)$ & $3.6(2.7)$ & $1.5(1.6)$ & $3.3(2.8)$ & $0^{* * *}$ \\
\hline Fatalities & Number & 0.831 & 0.125 & $0.1(0.3)$ & $0.1(0.3)$ & $0.1(0.3)$ & $0.2(0.4)$ & 0.087 \\
\hline
\end{tabular}

Source: Data from Field Survey 2017/18. Note: Figures in parenthesis indicate standard deviation. ${ }^{* * *}$ indicate significant at $1 \%$.

to plan proactive adaptation measures against climate risks. Walking distance to the nearest motor road, which in this case is also equivalent to the nearest market place, was assumed to be inversely related to adaptive capacity as households located far away from the markets would be in a disadvantageous position for lacking the opportunity of income generation from alternative sources like non-farm labor, which help in securing livelihoods during the periods of food shortage or crop failure.

Human asset: highest qualification in the family and the number of household members with trainings or vocational courses attended. It was supposed that development of human capabilities through vocational trainings or formal education would enable households to increase their income by undertaking skilled non-farm activities, which are less climate-sensitive compared to farming, thereby helping the households to avert climate risks. Furthermore, it would also diversify household livelihood sources which help to buffer the risks posed by climate on farm income.

Natural assets: The ownership of the total land utilized by the households, size of land owned and ownership of oxen. In the Kyoga plains there is a practice of 
Table 3. Adaptive Capacity Indicators across the sub counties.

\begin{tabular}{|c|c|c|c|c|c|c|c|}
\hline Indicator & Description of Indicator & Aggregate & Kisoko & Rubongi & Apopong & Kasodo & $\mathrm{P}$-value \\
\hline & & $\mathrm{n}=384$ & $\mathrm{n}=98$ & $\mathrm{n}=98$ & $\mathrm{n}=98$ & $\mathrm{n}=98$ & \\
\hline Non-income farm source & $\begin{array}{l}\text { Category, No other } 1 \text {, Business } \\
\text { 2, Bodaboda 3, Casual labour } 4\end{array}$ & 0.625 & $0.6(0.5)$ & $0.8(0.4)$ & $0.6(0.5)$ & $0.5(0.4)$ & $0^{* * *}$ \\
\hline Highest qualification & $\begin{array}{c}\text { School years, No education } 00, \\
\text { Primary } 7 \text {, Secondary } 15, \\
\text { Higher } 18\end{array}$ & 2.75 & $2.6(1.2)$ & $2.8(1.4)$ & $2.8(1.2)$ & $2.8(1.0)$ & 0.387 \\
\hline $\begin{array}{c}\text { Hold members with } \\
\text { vocational qualifications }\end{array}$ & Number & 0.5 & $0.7(0.9)$ & $0.5(0.8)$ & $0.4(1.0)$ & $0.4(0.7)$ & 0.061 \\
\hline $\begin{array}{l}\text { Relatives who support } \\
\text { during difficult times }\end{array}$ & Number & 0.575 & $0.6(0.5)$ & $0.6(0.4)$ & $0.6(0.5)$ & $0.7(0.5)$ & $0.001^{* * *}$ \\
\hline Type of house & $\begin{array}{l}\text { Category, Permanent } 1 \text {, Semi } \\
\text { permanent } 2 \text {, temporal } 3\end{array}$ & 2.2 & $2.4(0.8)$ & $2.3(0.9)$ & $1.5(0.7)$ & $2.6(0.7)$ & $0^{* * *}$ \\
\hline $\begin{array}{l}\text { Distance from the main } \\
\text { motorable road }\end{array}$ & Kilometres & 1.225 & $1.5(1.0)$ & $1.3(0.9)$ & $1.3(1.3)$ & $0.8(0.9)$ & $0^{* * *}$ \\
\hline $\begin{array}{c}\text { Ownership of devices-phones, } \\
\text { TV, Radio }\end{array}$ & Dummy, Yes 1, No 2 & 0.875 & $0.8(0.4)$ & $0.9(0.4)$ & $0.9(0.3)$ & $0.9(0.2)$ & 0.017 \\
\hline $\begin{array}{l}\text { Size of land owned } \\
\text { by house hold }\end{array}$ & Acres & 2.95 & $3.2(2.8)$ & $3.1(2.4)$ & $2.5(1.6)$ & $3.0(1.5)$ & $0.002^{* * *}$ \\
\hline $\begin{array}{l}\text { How additional land } \\
\text { used is obtained }\end{array}$ & Category, owned 1, Hired 2 & 0.575 & $0.6(0.5)$ & $0.7(0.5)$ & $0.4(0.5)$ & $0.6(0.5)$ & 0 \\
\hline 0wnership 0f oxen & Dummy Yes 1, No 2 & 0.3 & $0.1(0.3)$ & $0.2(0.4)$ & $0.3(0.5)$ & $0.6(0.5)$ & 0.002 \\
\hline Estimated annual income & Uganda shillings & 1147089 & $\begin{array}{c}1,294,050.0 \\
(1,825,718.6)\end{array}$ & $\begin{array}{c}659,760.0 \\
(1021168.7)\end{array}$ & $\begin{array}{l}1,241,914.9 \\
(150,610.3)\end{array}$ & $\begin{array}{c}1,392,631.6 \\
(1,285,353.8)\end{array}$ & 0.003 \\
\hline Estimated annual saving & Uganda shillings & 253500 & $\begin{array}{c}255,447.9 \\
(334,865.9)\end{array}$ & $\begin{array}{c}346,781.3 \\
(422129.9)\end{array}$ & $\begin{array}{c}183,299.2 \\
(1,656,812.5)\end{array}$ & $\begin{array}{c}228,541.7 \\
(183,635.7)\end{array}$ & 0.066 \\
\hline Livestock possession & Dummy, Yes 1, No 2 & 0.775 & $0.8(0.4)$ & $0.7(0.4)$ & $0.8(0.4)$ & $0.8(0.4)$ & 0.205 \\
\hline
\end{tabular}

Source: Data from Field Survey 2017/18; Note: Figures in parenthesis indicate standard deviation; ${ }^{* \star *}$ indicate significant at $1 \%$.

farmers using land beyond what one owns through renting to make up for land shortage. Households owning all the land that they use were assumed to be more flexible in production decision making and have lower production costs hence would suffer less from climate disasters. The other indicator was the size of land owned. Households that own big sizes of land were assumed to be more adaptive than those who own small sizes of land. Apart from that, the other indicator was possession of oxen. Households that possess oxen, which are the main means of plowing fields, were assumed able to have more timely preparation of gardens and production hence suffer less from climate disasters as compared to those without.

Financial assets: Gross household annual income, household savings, and owner ship of livestock (goat, poultry, cattle) were taken as the indicators of financial assets. Higher income means greater availability of resources at disposal to maximize positive livelihood outcomes. In addition to income at disposal, households that were able to make some savings out of their income would be able to make productive investments like family education or use the savings as buffer during the times of need. Households which own livestock were able to dispose them off during crisis and so were less vulnerable than those without. Apart from owning livestock, the number of these livestock that a household 
owned, was another indicator of adaptive capacity. Households with more livestock were considered more adaptive and hence less vulnerable than those with fewer.

Social asset: Having relatives who can support one during difficult times and the number of such relatives that a household would have. Having relatives who could support the household was considered a strong safety net against climate change challenges. Therefore, the households which were having relatives who support them were considered more adaptive than those who didn't. In addition, the higher the number of such relatives a household had, the more adaptive such a household was considered to be.

Having selected the appropriate indicators of farmer vulnerability, they were normalized or standardised so as to bring them within a comparable range [21] [22]. Normalisation was done by the general formula below as used by [10].

$$
\text { Index value }(\text { normalised value })=\frac{\text { Actual value }- \text { minimam value }}{\text { Maximam value }- \text { minimam value }}
$$

After standardizing the data, weights were then assigned to the indicators. As observed by [10], there are three methods in literature that are used to assign weights to indicators namely, expert judgment, arbitrary choice of choice of equal weight and Principle Component Analysis. The first two methods were however not preferred because expert judgment is constrained by availability of experts while arbitrary choice of equal weight is rather too subjective; besides, as literature shows, indicators do not equally affect vulnerability [10]. Assigning of weights was therefore done by Principal Component Analysis (PCA) in SPSS as suggested in [19] [21] [22] [23]. The weight assigned for each PCA indicator varies between -1 and +1 denoting the direction of the other indicators used to construct the respective vulnerability index. The magnitude of the weight describes the contribution of each indicator to the value of the index. PCA was then run separately for the indicators of exposure, sensitivity, and adaptive capacity. Step wise PCA was run for the indicators of exposure and adaptive capacity and overall indices calculated using the weights (loadings) obtained from second step PCA.

The normalised variables were then multiplied with the assigned weights to construct the indices for exposure, sensitivity and adaptive capacity, each separately using the equation below:

$$
I_{j}=\sum_{i=1}^{k} b_{i}\left[\frac{a_{j i}-x_{i}}{S_{i}}\right]
$$

where, " $P$ " is the value of the respective index (exposure, sensitivity and adaptive capacity), " $b$ " is the loadings from the first components from PCA (PCA1), taken as weights from respective indicators, " $a$ " is the indicator value, " $x$ " is the mean indicator value and " $s$ " is the standard deviation of the indicators. The vulnerability index for each house hold was then calculated as:

$$
V=(E+S)-A C
$$


where,

$V$ is the vulnerability index,

$E$ is the exposure index,

$S$ is the sensitivity index and

$A C$ is the adaptive capacity index for respective households.

The overall vulnerability index for each household was then calculated. Higher value of the vulnerability index indicates higher vulnerability. However negative value of the index does not imply that the household is not vulnerable at all. This index does not give the absolute measurement of vulnerability; rather the index values give a comparative ranking of the sampled households and study villages, parishes, sub counties and districts within the study area. For this paper, vulnerability for each household was amalgamated to the sub county level to enable an inter sub county comparison across the study area.

Tests of analysis of variance (ANOVA) were then be conducted to compare the means among the different households, villages, parishes, sub counties and districts in order to determine the spatial differentiation in vulnerability to climate change among the small holder farmers in the Kyoga plains of Uganda.

Household vulnerability indices were also cross tabulated against the ten socio economic characteristics of the households namely, gender, age, farming experience, farm size, income level, access to credit, access to extension services, household size, educational level and membership to a support groups so as to determine the variation of vulnerability of smallholder farmers within these socio-economic groups.

\section{Results and Discussion}

The index scores for sensitivity, exposure, adaptive capacities and overall vulnerability for each individual household were aggregated at the village, parish, Sub County and district levels. This study uses the sub county level scores of exposure, sensitivity, adaptive capacity and overall vulnerability for analysis because the Sub County is an administrative unit of government authorized to plan and implement development plans.

\subsection{Indicators of Exposure}

The weights obtained from PCA analysis for the indicators of exposure (Table 1) ranged from 0.99 (maximum temperature) to -0.97 (minimum). The weights for the indicators of exposure are all positive as hypothesized except for minimum temperature trend. This shows that while maximum temperature trend, rainfall trend and number of extreme climate events contribute positively to the exposure index, minimum temperature contributes in the opposite direction. The absolute value of the weights indicates that maximum temperature and extreme climate event trends contribute slightly more to the exposure index compared to the incidence of rainfall. This seems to be in tandem with [9] who in a study in Malawi, indicates that extreme climate events and rainfall change had the highest 
and positive loadings. Similar studies by [24] and [25] showed that incidents of meteorological, hydro meteorological and agricultural droughts lead to massive crop failures thereby increasing the exposure of the farmers. Following the mean values of the indicators of exposure shows that they varied with sub counties for instance, minimum temperature was highest in Kasodo and lowest in Apopong, both in Pallisa. Maximum temperature on the other hand was highest in Apopong and lowest in Kasodo. This implies that temperature was slightly higher in Pallisa than Tororo and this is perhaps because Pallisa is at a lower altitude than Tororo. Rainfall was slightly higher in Rubongi, Tororo though the sub county with the lowest amount of rainfall was Kisoko, also in Tororo. The highest frequency of extreme climate events in the last ten years occurred in Kasodo sub county, Pallisa district while the lowest was reported in Apopong, also in Pallisa.

\subsection{Sensitivity Indicators}

Indicators of sensitivity are contributing to the sensitivity index in the direction as hypothesized (Table 2). They ranged from 0.898 (Value of crops lost due to drought and floods both in the garden and stores in Ug shs) to -0.758 (How often do you experience outbreaks of cholera and other diseases?). From the weights of the sensitivity indicators, value of crops lost (0.898), household property lost (0.864) and number fatalities (0.831) are seen to contribute more to the overall sensitivity index compared to the other indicators. This is in contrast with [23] who in a study in Himachal Pradesh, India, indicated that number of livestock killed and physical property destroyed by extreme events contributed least to the sensitivity index as shown by their respective weights. Outbreaks of cholera and other diseases have given the least contribution to the sensitivity index (as shown by negative sign of the weight). However, this does not mean that it assists to decrease the overall household sensitivity. This negative sign is perhaps due to the improved level of intervention with which government responds whenever such out breaks occur such that it does not lead to many fatalities in most cases. The contribution of sensitivity indicators to the overall sensitivity index varied across the sub counties for instance, effects of climate events were most felt in Kasodo sub county (Pallisa district), the value of household property lost due to floods was highest in Kisoko (Tororo district) and the number of livestock lost as a result of drought and floods was highest in Kisoko, Tororo district. The value of crops lost due to floods and drought was highest in Apopong while other losses incurred as a result of climate events were almost uniformly felt across the sub counties except for Apopong, which on the other hand experienced the highest frequency of cholera and other diseases outbreak. Rubongi Sub County reported the highest number of household numbers who fell victim of disease outbreaks while the number of fatalities was almost uniform across the sub counties except for Kasodo, Pallisa district which reported a slightly higher number. This indicates that there is a spatial variation in the level of sensitivity across the agro ecological zone. 


\subsection{Adaptive Capacity Indicators}

Mean average values of the indicators for adaptive capacity (Table 3) revealed that Kasodo had a comparatively higher asset possession. It led in four asset categories namely, number of relatives who support during livelihood challenges (0.7) with Rubongi trailing at (0.4), type of house owned (2.6), with Apopong trailing at (1.5), number of oxen owned (0.6) with Kisoko trailing at (0.1) and annual savings $(1,392,631.2)$. Kisoko and Rubongi led in three asset categories each while Apopong was the least only managing to be at the same level with others in two asset categories namely, highest qualification obtained by a household member (2.8), together with Kasodo and Rubongi) and possession of livestock (0.8), together with Kasodo and Kisoko).

First step PCA revealed that among the physical assets, ownership of communication devices had the highest influence (0.728) followed by the type of house owned $(0.6450)$ then distance to the nearest motor able road $(-0.587)$. Distance to the nearest motor able road influenced the adaptive capacity negatively as indicated by the negative sign of its weight.

Among the human assets, the highest education level obtained by a household member and the number of family members with qualification in vocational training got the same weight (0.813). All had a positive influence on the adaptive capacity. Under natural assets, the size of land owned got the highest weight (0.828) followed by ownership of the additional land used (0.728) and then ownership of oxen for plowing got the least weight (0.593). All these had a positive influence on adaptive capacity. For financial assets, estimated annual income had the highest weight $(0.8690)$ followed by estimated annual saving and possession of livestock (0.15). Social assets did not register any weight under step 1 PCA and therefore was not considered under step 2 PCA.

The second-step PCA showed that financial assets are the most important determinants of the overall adaptive capacity followed by human, natural and physical assets. Financial asset is very important as it is the most flexible and therefore convenient form of asset that can be converted into other forms of asset whenever needed. Development of human assets in terms of education and skill development trainings is only possible when there is financial asset. In addition, financial asset is very necessary in order to be able to properly develop and utilize the existing physical and financial assets. Furthermore, natural assets are crucial because they are the basis on which the other assets are applied so as to improve livelihood. It has got the third position in weight perhaps because of the fact that natural assets are more impacted upon by climate change and related disasters as compared to other asset types. Physical assets got the lowest weight but are very important because they enhance extraction and utilization of natural assets for example, roads help to increase access to services such as fertilisers, planting materials as well as markets for agricultural products. Communication devices on the other hand help to improve access to climate change information as well as market access while type of house owned determines the level of 
protection that people will get from the direct impact of extreme climate events especially floods. Social assets did not get any weight. Thus as noted by [26] in a study in central and western Uganda, improving adaptive capacity would require that farmers engage in off farm self-employment.

\subsection{Vulnerability Indices}

Examining the vulnerability index (Table 4) revealed that Kasodo was the most vulnerable sub county (10.0) while Rubongi was the least vulnerable (-3.5). Apopong (-11.1) and Kisoko (3.6) rank the second and third respectively. Kasodo had the highest exposure (9.8) coupled with the second lowest adaptive capacity $(-0.3)$ and as a result, it was the most vulnerable sub county. Apopong on the other hand, despite having the lowest adaptive capacity $(-0.5)$ ranked the second least vulnerable sub county owing to its low exposure index $(-8.8)$. Despite having a comparatively higher adaptive capacity than Apopong (0.4), Kisoko was third in overall vulnerability (3.4) because it had a higher exposure index (3.4). Further examination of the two least vulnerable sub counties revealed that both were similar in terms of having negative exposure index (Apopong -8.8 , Rubongi -3.1$)$, Apopong had a slightly lower sensitivity index (-0.1 compared to Rubongi 0.1$)$ and a much lower adaptive capacity $(-0.5)$ which resulted in higher vulnerability there compared to Rubongi. This is in tandem with Coulibaly et al., 2015, who show spatial variation in vulnerability by district in a study conducted in Malawi.

An inter district variation in the level of vulnerability is shown in (Figure 2) to complement the findings above. Accordingly, Pallisa district was found to be more vulnerable than Tororo district.

\subsection{Vulnerability in Relation to Farmers' Socioeconomic Characteristics}

Apart from examining the level of vulnerability among farmers in the different sub counties to determine the spatial extent, vulnerability index was also cross tabulated with the socioeconomic characteristics of the farmers across the study area. To this end it was found that vulnerability levels vary with different socioeconomic characteristics of the respondents as follows.

\subsubsection{Age}

Vulnerability levels varied across the age groups with age group less than 30 years showing the highest vulnerability level (2.4) and the lowest being age group 50 - 59 (-1.0) age groups 30 - 39 (1.7), 40 - 49 (1.5) and 60 above (0.4), were second, third and fourth respectively, with a P-value of 0.526 , which is not significant. A survey of literature revealed that there is no consensus on the effect of age on vulnerability to climate change. On the one hand, age may have a negative effect on the decision to adopt new farming techniques and therefore increase vulnerability simply because older farmers may be more risk-averse and therefore, less likely to be flexible than younger farmers. On the other hand, age 
Table 4. Index scores for vulnerability and it's components across the sub counties.

\begin{tabular}{ccccc}
\hline Component & Kisoko & Apopong & Kasodo & Rubongi \\
\hline Exposure & 3.38 & -8.76 & 9.77 & -3.12 \\
Sensitivity & 0.07 & -0.15 & -0.12 & 0.14 \\
Adaptive Capacity & 0.38 & -0.46 & -0.31 & 0.44 \\
Vulnerability & 3.63 & -11.09 & 9.99 & -3.48 \\
\hline
\end{tabular}

Source: Data from Field Survey 2017/18.

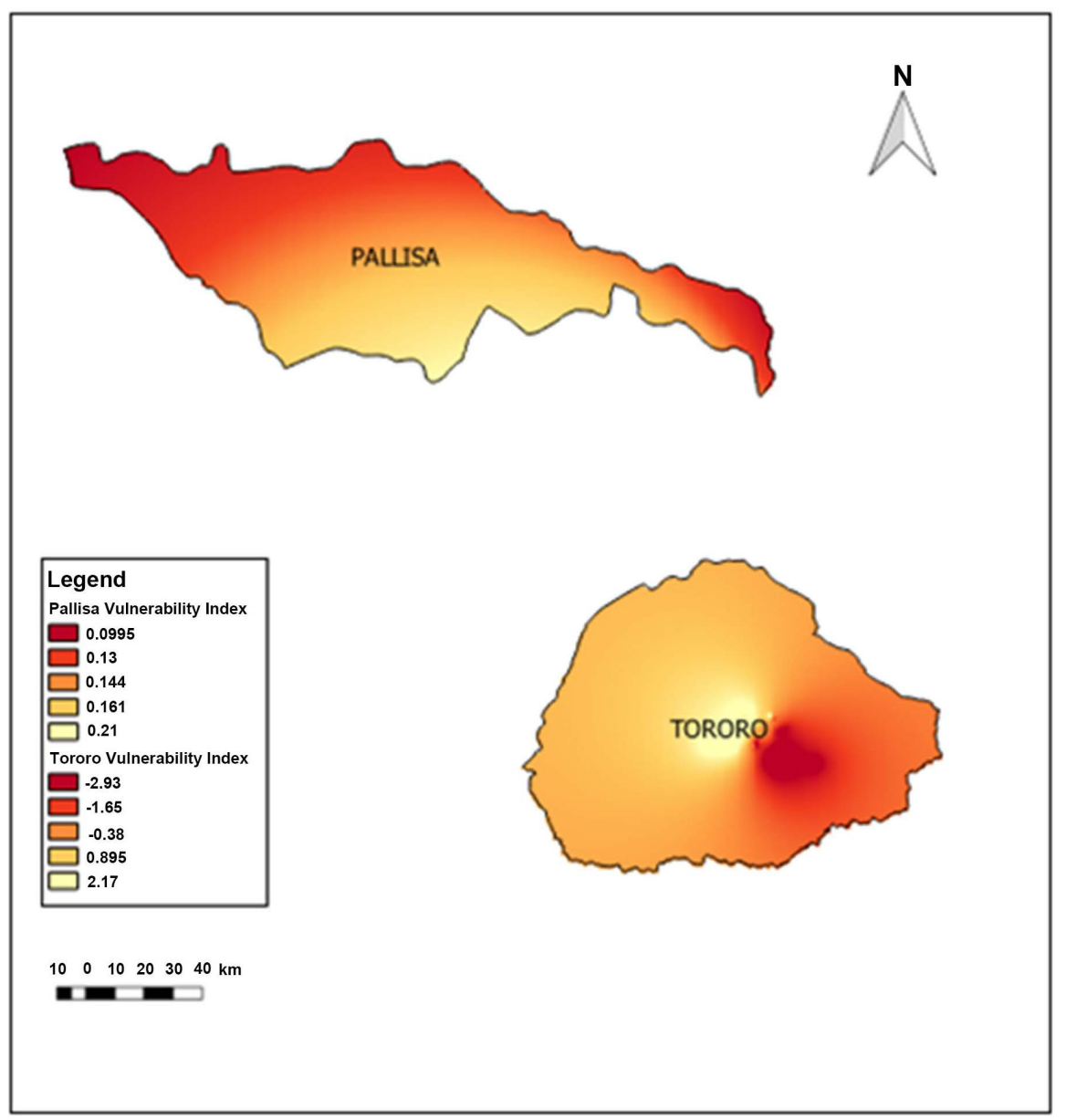

Figure 2. Map showing vulnerability indices across the districts (Authors' own design, not drawn to scale).

may have a positive effect on the decision of the farmer to adopt and therefore reduce vulnerability because older farmers may have more experience in farming and therefore, better able to assess the features of a new farming technology than the younger farmers [22] [27]. This applies to vulnerability such that age may not necessarily have a negative or positive effect to farmers' vulnerability to climate change. In this study we hypothesized that age of the farmer has positive impact on vulnerability to climate change. The findings indicate that there is a positive relationship between age and vulnerability, that is, the older farmers are 
less vulnerable to climate change and vice versa. However, this relationship is not significant meaning that the age of the farmer may not determine their level of vulnerability.

\subsubsection{Farming Experience}

The highest level of vulnerability was noted among farmers with farming experience of between 20 - 30 years (2.3), followed by those with less than twenty years' experience (2.1) and then those of $41-50$ years (0.3). Those of $31-40$ $(-3.9)$ and 50 and above years $(-2.5)$, were the last and second last respectively. The P-value here is 0.074 . Studies on agricultural technology adoption to reduce vulnerability by [22] [27] observes that there is no consensus in the literature as to the exact effect of farming experience in influencing vulnerability through the adoption of farming technologies because the experience effect is generally location or technology specific and hence an empirical question. On one hand, farming experience may have a negative effect on the level of vulnerability through decision to adopt new farming techniques simply because more experienced farmers may be more risk-averse and therefore less flexible than less experienced farmers. On the other hand, experience may have a positive effect on vulnerability through the decision of the farmer to adopt because older farmers may have more experience in farming and therefore better able to assess the features of a new farming technology than the less experienced farmers and so avert vulnerability. In this study it was hypothesized that experience of the farmer would lead to reduced vulnerability to climate change. The results show a positive correlation which implies that the more experience farmers have the less vulnerable they are to climate change. However, this correlation is not significant implying that farming experience may not significantly reduce the vulnerability of farmers to climate change. This is perhaps because despite being able to assess the features of new technology by virtue of their experience, many of them did not have the resources to acquire the necessary new technology that would boost their productivity and hence adaptive capacity there by reducing their vulnerability.

\subsubsection{Gender}

The males were reported to have a higher level of vulnerability (1.1) than the female farmers (0.6), with a P-value of 0.689. Various studies have shown that gender is an important variable affecting the level of vulnerability through adaptation decision at the farm level. Female farmers have been found to be more likely to adopt natural resource management and conservation practices and therefore be less vulnerable [28] [29]. However, [30] note that households headed by males have a higher probability of being less vulnerable by getting information about new farming techniques and also undertake more risky ventures than female headed households. A similar observation is made by [31] who point out that female headed households are less likely to adopt soil and water conservation measures since women may have restricted access to information, 
land, and other resources due to traditional social barriers. Nonetheless, [32] have contrary results to the effect that female headed households are more likely to adopt different methods of climate change adaptation than male headed households hence are less vulnerable than their male counterparts. Gender variation may equally have different effects on the level of vulnerability since the concepts are closely related and one aspect leads to the other. Some studies on the other hand found that household gender was not a significant factor influencing farmers' level of vulnerability to climate change through decisions to adopt conservation measures [33]. In this study, it was hypothesized that the gender of the household head would have a significant influence on the household's level of vulnerability to climate change. Our findings show that the male headed households are more vulnerable to climate change than the females. However, the relationship is not significant meaning that the gender of the household head is not significant enough to influence the level of vulnerability.

\subsubsection{Level of Education}

The highest level of vulnerability was reported amongst farmers with secondary level education (3.1) followed by those with primary level (1.1) and then those with higher education level $(-0.6)$. Those with no formal education were reported to be least vulnerable $(-1.8)$. The $\mathrm{P}$-value was 0.094 .

Literature is equally divided on the influence of education on vulnerability to climate change. Studies have shown that improving education and disseminating knowledge is an important policy measure for stimulating local participation in various development and natural resource management initiatives hence reducing vulnerability [28] [32] [34] [35] [36]. Better education improves awareness of potential benefits and willingness to participate in local natural resource management and conservation activities. Farmers with more education are more likely to have enhanced access to technological information than poorly educated farmers. Educated farmers are expected to have more knowledge and information about climate change and agronomic practices that they can use in response to reduce vulnerability to climate change [32] and [37]. However, [38] found that education was an insignificant determinant of adoption decisions hence does not reduce vulnerability while [39] [40] [41] found that education was negatively correlated with such decisions. In this study it was hypothesized that educated farmers are less vulnerable to climate change. The findings show that there is a positive correlation between the farmers' level of education and vulnerability to climate change, that is, more educated farmers are less vulnerable to climate change. However, the level of this correlation is not significant, that is, the level of education does not reduce a farmer's vulnerability as indicated by [38].

\subsubsection{Farm Size}

Vulnerability levels were found to be highest among farmers with farms ranging from 4.1 - 6 acres (3.0) followed by those with farms between 2 - 4 acres (1.0). 
Those with farms of over 6 acres were the least vulnerable $(-5.5)$ while those with less than two acres (0.3), were second last. The P-value was 0.222 . Available literature indicates mixed effects of farm size on vulnerability to climate change for example a study on soil conservation measures in South Africa showed that farm size was not a significant adoption factor and therefore does not influence the level of vulnerability to climate change [42]. Other studies, however, found that farmers with larger farms were found to have more land to allocate for constructing soil bunds (embankments), improved cut-off drains in Haiti and grow both perennial and annual crops which would improve their adaptative capacity, thereby reducing their vulnerability [35] [39] [43]. On the other hand, [44] found that farmers with a small area of land were more likely to invest in soil conservation than those with a large area and therefore be less vulnerable. In this study it was hypothesized that farmers with larger farms are less vulnerable to climate change than those with smaller farms. Our findings indicate that there was a positive relationship between farm size and the level of vulnerability implying that farmers with larger farms are more vulnerable to climate change but this correlation is not significant, that is, the size of the farm is not significant enough to determine the level of vulnerability of a farmer to climate change. This finding appears contradictory to the general truth that would be expected. However, it is true because many of the farmers with large size of land were lacking the requisite resources and other capacities that could enable them use the land effectively for example some who did not have oxen for plowing found it expensive to grow sufficient crops and so only have the little, they could do with their house hold labour.

\subsubsection{Level of Income}

Farmers with a monthly income of 10,000 - 100,000 were reported to be the most vulnerable (2.1) followed by those with between 101,000 - 200,000 (1.1) and then those with 201,000 - 300,000. Those with less than 10,000 (-6.5) and those with over $300000(-3.1)$, were the last and second last respectively, with a $\mathrm{P}$-value of $0.017^{\star * *}$. This is in line with the available literature which seems unanimous to the effect that income of the farmers, whether farm or nonfarm, represents the wealth of individual households. Empirical evidence by [45] and [46] indicate that farmers' income has a positive relationship with the uptake of farming technologies and therefore reduction in vulnerability since any adoption/adaptation process requires that the farmer has sufficient financial wellbeing. Higher income positively affects public perception of climate change [47] [48].

\subsubsection{Group Membership}

Vulnerability was reported to be highest among the farmers belonged to support groups (1.5) as compared to those who did not belong to any group ( -0.5$)$ with a $\mathrm{P}$-value of 0.157 . Literature indicates that farmer-to-farmer extension and the number of relatives in the Got (village) represent social capital, which plays a 
significant role [49] [50] in information exchange. Other social networks are also formed through membership in village associations for example village savings and credit schemes, village burial associations, farmer groups and so on. These organizations facilitate information flow among the farmers. It was assumed that farmers who belong to social support groups are less vulnerable to climate change than those who do not. The findings however show that vulnerability is higher among those in social groups but the relationship is not significant. This implies that social network does not determine the level of vulnerability.

\subsubsection{Access to Extension Workers}

Farmers who had access to extension workers had a higher vulnerability index (1.2) than those who did not have (0.3). The P-value was 0.335. Literature indicates that extension services are an important source of information on agronomic practices as well as on climate. Extension education was found to be an important factor motivating increased intensity of use of specific soil and water conservation practices [33] [36] [51] [52] [53] which ultimately reduces vulnerability to climate change. Other studies, however, have found that extension was not a significant factor affecting the level of farmers' vulnerability to climate change [54] [55]. The findings above are in line with this.

\subsubsection{Access to Credit}

An examination into the vulnerability index of farmers according to their access to credit revealed that those had access had a higher vulnerability index (1.8) than those without (0.4) and the P-value was (0.335) This seems to be in line with available literature which notes the role of credit in the uptake of farming technologies. [36] [56] and [57] observe that a positive relationship exists between the level of adoption and the availability of credit since credit eases the cash constraints and allows farmers to buy inputs such as fertilizer, improved crop varieties and irrigation facilities which reduces vulnerability. Our findings however indicate that the relationship is not significant though positive.

\subsubsection{Household Size}

Vulnerability was found to be highest amongst those with families of fifteen and above members (6.0) followed by those with families of ten to fifteen members (1.9) then families of five to 9 members (0.8) and lastly families with less than five members were the least vulnerable $(-0.6)$ and the P-value was (0.074). As for the household size, [48], argue that larger households have a larger pool of labour and as a result, they are more likely to adopt agricultural techniques than smaller households. Moreover, [36] notes that the size of the household influences individuals' adaptation to climate change in two perspectives. In the first perspective, households with large families may be forced to divert part of the labour force from farm to off-farm activities in an attempt to earn some income that can ease the consumption pressure imposed by a large family in the face of climate change. In the second perspective, households with a large family size are considered to have a larger pool of cheap labour resource, which can readily 
be employed on the farm for crop and/or livestock production, unlike families with smaller household size. The findings affirm the assumption that farmers with large households may be more vulnerable to climate change due high dependency ratio. However, the correlation is not significant.

\section{Conclusions and Policy Recommendations}

The analyses brought up three main ideas of the vulnerability of farmers of the Kyoga plains to climate change sector to climate change.

First and foremost, overall vulnerability to climate change is spatially differentiated across the agro ecological zone. Vulnerability indices differ in the different sub counties that were picked for analysis, for instance, Kasodo was the most vulnerable sub county with the highest level of exposure and second lowest level of adaptive capacity while Apopong with the least level of adaptive capacity was the second least vulnerable with the least exposure implying that the three elements of vulnerability occur at different levels in different areas in the agro-ecological zone. Thus, although national and regional/zonal climate change adaptation policy is necessary, policymakers should develop area-specific policies and address climate change at the lower level (zones and sub zones) depending on their unique characteristics.

Secondly, whereas results show that exposure of a locality to long-term changes in climate variables and occurrences of natural disasters are the most important component to determine the overall vulnerability of the locality, biophysical elements determining the exposure like temperature, rainfall and natural disasters are beyond the immediate influence of the policy makers. Out of the three components of vulnerability, adaptive capacity is the component having direct policy implications. Thus, improving the adaptive capacity of these vulnerable households should be the main focus of policy formulation and implementation since improved adaptive capacity reduces their sensitivity and finally decreases their overall vulnerability. Among the various components of adaptive capacity, policy emphasis should be placed to create opportunities for non-farm livelihoods options which will reduce the dependence of the community on natural resources. Besides, relief measures to support the community during emergencies must be put in place for all the sub counties having both higher exposure as well as lesser adaptive capacity.

\section{Acknowledgements}

The authors are grateful to Swedish International Development Agency (Sida) and Makerere University under Sida Grant Contribution No: 5180060 for funding PhD studies for the first author. The support from the Doctoral committee and facilities provided by the Department of Geography, Geo informatics and Climatic Sciences, School of Forestry Environmental and Geographical Sciences, College of Agricultural Sciences, Makerere University, Uganda, are highly appreciated. We also appreciate the anonymous reviewers for their inciteful comments that strengthened our paper further. 


\section{Conflicts of Interest}

The authors declare no conflicts of interest regarding the publication of this paper.

\section{References}

[1] MoFPED (2014) Poverty Status Report; Structural Change and Poverty Reduction National Assessment) (p 156). M. o. F. P. a. E. Development, Ed., MoFPED, Kampala.

[2] Hisali, E., Birungi, P. and Buyinza, F. (2011) Adaptation to Climate Change in Uganda: Evidence from Micro Level Data. Global Environmental Change, 21, 1245-1261. https://doi.org/10.1016/j.gloenvcha.2011.07.005

[3] Mubiru, D.N., Komutunga, E., Agona, A., Apok, A. and Ngara, T. (2012) Characterising Agrometeorological Climate Risks and Uncertainties: Crop Production in Uganda. South African Journal of Science, 108, 108-118.

https://doi.org/10.4102/sajs.v108i3/4.470

[4] Epule, T.E., Ford, J.D., Lwasa, S. and Lepage, L. (2017) Vulnerability of Maize Yields to Droughts in Uganda. Water, 9, 181. https://doi.org/10.3390/w9030181

[5] Nabikolo, D., Bashaasha, B., Mangheni, M. and Majaliwa, J. (2012) Determinants of Climate Change Adaptation among Male and Female Headed Farm Households in Eastern Uganda. African Crop Science Journal, 20, 203-212.

[6] Tukezibwa, D. (2010) Farmers' Vulnerability and Adaptation to Climate Change around Queen Elizabeth National Park-Uganda.

[7] Rusinga, O., Chapungu, L., Moyo, P. and Stigter, K. (2014) Perceptions of Climate Change and Adaptation to Microclimate Change and Variability among Smallholder Farmers in Mhakwe Communal Area, Manicaland Province, Zimbabwe. Ethiopian Journal of Environmental Studies and Management, 7, 310-318. https://doi.org/10.4314/ejesm.v7i3.11

[8] Ndaki, P.M. (2014) Climate Change Adaptation for Smallholder Farmers in Rural Communities: The Case of Mkomazi Sub-Catchment, Tanzania. Oldenburg-Carl von Ossietzky University of Oldenburg.

[9] Coulibaly, J.Y., Mbow, C., Sileshi, G.W., Beedy, T., Kundhlande, G. and Musau, J. (2015) Mapping Vulnerability to Climate Change in Malawi: Spatial and Social Differentiation in the Shire River Basin. American Journal of Climate Change, 4, 282-294. https://doi.org/10.4236/ajcc.2015.43023

[10] Gbetibouo, G.A., Ringler, C. and Hassan, R. (2010) Vulnerability of the South African Farming Sector to Climate Change and Variability: An Indicator Approach. Natural Resources Forum, 34, 175-187. https://doi.org/10.1111/j.1477-8947.2010.01302.x

[11] Wortmann, C.S. and Eledu, C.A. (1999) An Agroecological Zonation of Uganda: Methodology and Spatial Information, Network for Bean Research in Africa, Occasional Paper Series No. 30, CIAT, Kampala, Uganda.

[12] Authority, N.E.M. (2006) State of the Environment Report for Uganda. MWE, Ed., NEMA, Kampala, 36-37.

[13] McSweeney, C., New, M., Lizcano, G. and Lu, X. (2010) The UNDP Climate Change Country Profiles: Improving the Accessibility of Observed and Projected Climate Information for Studies of Climate Change in Developing Countries. Bulletin of the American Meteorological Society, 91, 157-166. https://doi.org/10.1175/2009BAMS2826.1 
[14] Lwasa, S. (2018) Drought and Flood Risk, Impacts and Adaptation Options for Resilience in Rural Communities of Uganda. International Journal of Applied Geospatial Research (IJAGR), 9, 36-50. https://doi.org/10.4018/IJAGR.2018010103

[15] Abrha, M.G. and Simhadri, S. (2015) Local Climate Trends and Farmers' Perceptions in Southern Tigray, Northern Ethiopia. American Journal of Environmental Sciences, 11, 262-277. https://doi.org/10.3844/ajessp.2015.262.277

[16] Lewis, P. (2007) Summary for Policymakers of the Synthesis Report of the IPCC Fourth Assessment Report.

[17] Füssel, H.-M. and Klein, R.J. (2006) Climate Change Vulnerability Assessments: An Evolution of Conceptual Thinking. Climatic Change, 75, 301-329. https://doi.org/10.1007/s10584-006-0329-3

[18] McCarthy, J.J., Canziani, O.F., Leary, N.A., Dokken, D.J. and White, K.S. (2001) Climate Change 2001: Impacts, Adaptation, and Vulnerability. Contribution of Working Group II to the Third Assessment Report of the Intergovernmental Panel on Climate Change Vol. 2. Cambridge University Press, Cambridge.

[19] Tesso, G., Emana, B. and Ketema, M. (2012) Analysis of Vulnerability and Resilience to Climate Change Induced Shocks in North Shewa, Ethiopia. Agricultural Sciences, 3, 871. https://doi.org/10.4236/as.2012.36106

[20] Luers, A.L., Lobell, D.B., Sklar, L.S., Addams, C.L. and Matson, P.A. (2003) A Method for Quantifying Vulnerability, Applied to the Agricultural System of the Yaqui Valley, Mexico. Global Environmental Change, 13, 255-267. https://doi.org/10.1016/S0959-3780(03)00054-2

[21] Piya, L., Maharjan, K.L. and Joshi, N.P. (2012) Vulnerability of Rural Households to Climate Change and Extremes: Analysis of Chepang Households in the Mid-Hills of Nepal. 18-24.

[22] Gbetibouo, G.A. and Ringler, C. (2009) Mapping South African Farming Sector Vulnerability to Climate Change and Variability: A Subnational Assessment.

[23] Ndugu, C.K., Bhardwaj, S., Sharma, D., Sharma, R., Gupta, R. and Sharma, B. (2015) Vulnerability Assessment of Rural Communities to Environmental Changes in Mid-Hills of Himachal Pradesh in India.

[24] Vishwa, B., Chandel, S. and Karanjot, K. (2013) Drought in Himachal Pradesh, India: A Historical-Geographical Perspective, 1901-2009. Transactions, 35, 260-273.

[25] Vedwan, N. (2006) Culture, Climate and the Environment: Local Knowledge and Perception of Climate Change among Apple Growers in Northwestern India. Journal of Ecological Anthropology, 10, 4-18. https://doi.org/10.5038/2162-4593.10.1.1

[26] Bagamba, F., Bashaasha, B., Claessens, I. and Antle, J. (2012) Assessing Climate Change Impacts and Adaptation Strategies for Smallholder Agricultural Systems in Uganda. African Crop Science Journal, 20, 303-316.

[27] Gbetibouo, G.A. (2009) Understanding Farmers' Perceptions and Adaptations to Climate Change and Variability: The Case of the Limpopo Basin, South Africa. Intl Food Policy Res Inst., 849.

[28] Dolisca, F., Carter, D.R., McDaniel, J.M., Shannon, D.A. and Jolly, C.M. (2006) Factors Influencing Farmers' Participation in Forestry Management Programs: A Case Study from Haiti. Forest Ecology and Management, 236, 324-331. https://doi.org/10.1016/j.foreco.2006.09.017

[29] Bayard, B., Jolly, C.M. and Shannon, D.A. (2007) The Economics of Adoption and Management of Alley Cropping in Haiti. Journal of Environmental Management, 84, 62-70. https://doi.org/10.1016/j.jenvman.2006.05.001 
[30] Asfaw, A. and Admassie, A. (2004) The Role of Education on the Adoption of Chemical Fertiliser under Different Socioeconomic Environments in Ethiopia. Agricultural Economics, 30, 215-228. https://doi.org/10.1111/j.1574-0862.2004.tb00190.x

[31] Tenge, A., De Graaff, J. and Hella, J. (2004) Social and Economic Factors Affecting the Adoption of Soil and Water Conservation in West Usambara Highlands, Tanzania. Land Degradation \& Development, 15, 99-114. https://doi.org/10.1002/ldr.606

[32] Hassan, R. and Nhemachena, C. (2008) Determinants of African Farmers' Strategies for Adapting to Climate Change: Multinomial Choice Analysis. African Journal of Agricultural and Resource Economics, 2, 83-104.

[33] Bekele, W. and Drake, L. (2003) Soil and Water Conservation Decision Behavior of Subsistence Farmers in the Eastern Highlands of Ethiopia: A Case Study of the Hunde-Lafto Area. Ecological Economics, 46, 437-451. https://doi.org/10.1016/S0921-8009(03)00166-6

[34] Glendinning, A., Mahapatra, A. and Mitchell, C.P. (2001) Modes of Communication and Effectiveness of Agroforestry Extension in Eastern India. Human Ecology, 29, 283-305. https://doi.org/10.1023/A:1010954631611

[35] Anley, Y., Bogale, A. and Haile-Gabriel, A. (2007) Adoption Decision and Use Intensity of Soil and Water Conservation Measures by Smallholder Subsistence Farmers in Dedo District, Western Ethiopia. Land Degradation \& Development, 18, 289-302. https://doi.org/10.1002/ldr.775

[36] Tizale, C.Y. (2007) The Dynamics of Soil Degradation and Incentives for Optimal Management in the Central Highlands of Ethiopia. University of Pretoria, Pretoria.

[37] Maddison, D. (2007) The Perception of Adaptation to Climate Change in Africa. The World Bank Development Research Group Sustainable Rural and Urban Development Team, Policy Research Working Paper 4308.

https://doi.org/10.1596/1813-9450-4308

[38] Clay, D., Reardon, T. and Kangasniemi, J. (1998) Sustainable Intensification in the Highland Tropics: Rwandan Farmers' Investments in Land Conservation and Soil Fertility. Economic Development and Cultural Change, 46, 351-377. https://doi.org/10.1086/452342

[39] Okoye, C. (1998) Comparative Analysis of Factors in the Adoption of Traditional and Recommended Soil Erosion Control Practices in Nigeria. Soil and Tillage Research, 45, 251-263. https://doi.org/10.1016/S0933-3630(96)00137-7

[40] Ajak, B.J., Kyazze, F.B. and Mukwaya, P.I. (2018) Choice of Adaptation Strategies to Climate Variability among Smallholder Farmers in the Maize Based Cropping System in Namutumba District, Uganda. American Journal of Climate Change, 7, 431. https://doi.org/10.4236/ajcc.2018.73026

[41] Gould, B.W., Saupe, W.E. and Klemme, R.M. (1989) Conservation Tillage: The Role of Farm and Operator Characteristics and the Perception of Soil Erosion. Land Economics, 65, 167-182. https://doi.org/10.2307/3146791

[42] Anim, F.D. (1999) A Note on the Adoption of Soil Conservation Measures in the Northern Province of South Africa. Journal of Agricultural Economics, 50, 336-345. https://doi.org/10.1111/j.1477-9552.1999.tb00818.x

[43] Mugagga, F. (2017) Perceptions and Response Actions of Smallholder Coffee Farmers to Climate Variability in Montane Ecosystems. Environment and Ecology Research, 5, 357-366. https://doi.org/10.13189/eer.2017.050505 
[44] Juma, M., Nyangena, W. and Yesuf, M. (2009) Production Risk and Farm Technology Adoption in Rain-Fed, Semi-Arid Lands of Kenya. Environment for Development Discussion Paper Series, 09-22.

[45] Franzel, S. (1999) Socioeconomic Factors Affecting the Adoption Potential of Improved Tree Fallows in Africa. Agroforestry Systems, 47, 305-321. https://doi.org/10.1023/A:1006292119954

[46] Knowler, D. and Bradshaw, B. (2007) Farmers' Adoption of Conservation Agriculture: A Review and Synthesis of Recent Research. Food Policy, 32, 25-48. https://doi.org/10.1016/j.foodpol.2006.01.003

[47] Semenza, J.C., Hall, D.E., Wilson, D.J., Bontempo, B.D., Sailor, D.J. and George, L.A. (2008) Public Perception of Climate Change: Voluntary Mitigation and Barriers to Behavior Change. American Journal of Preventive Medicine, 35, 479-487. https://doi.org/10.1016/j.amepre.2008.08.020

[48] Deressa, T.T., Hassan, R.M., Ringler, C., Alemu, T. and Yesuf, M. (2009) Determinants of Farmers' Choice of Adaptation Methods to Climate Change in the Nile Basin of Ethiopia. Global Environmental Change, 19, 248-255. https://doi.org/10.1016/j.gloenvcha.2009.01.002

[49] Isham, J. (2002) The Effect of Social Capital on Fertiliser Adoption: Evidence from Rural Tanzania. Journal of African Economies, 11, 39-60. https://doi.org/10.1093/jae/11.1.39

[50] Isham, J. (2000) The Effect of Social Capital on Technology Adoption: Evidence from Rural Tanzania.

[51] Asfaw, D. and Neka, M. (2017) Factors Affecting Adoption of Soil and Water Conservation Practices: The Case of Wereillu Woreda (District), South Wollo Zone, Amhara Region, Ethiopia. International Soil and Water Conservation Research, 5, 273-279. https://doi.org/10.1016/j.iswcr.2017.10.002

[52] Pereira de Herrera, A. and Sain, G. (1999) Adoption of Maize Conservation Tillage in Azuero. CIMMYT, Panama.

[53] Baidu-Forson, J. (1999) Factors Influencing Adoption of Land-Enhancing Technology in the Sahel: Lessons from a Case Study in Niger. Agricultural Economics, 20, 231-239. https://doi.org/10.1016/S0169-5150(99)00009-2

[54] Pender, J., Ssewanyana, S., Edward, K. and Nkonya, E. (2004) Linkages between Poverty and Land Management in Rural Uganda: Evidence from the Uganda $\mathrm{Na}$ tional Household Survey, 1999/00. Intl Food Policy Res Inst.

[55] Nkonya, E., Kaizzi, C. and Pender, J. (2005) Determinants of Nutrient Balances in a Maize Farming System in Eastern Uganda. Agricultural Systems, 85, 155-182. https://doi.org/10.1016/j.agsy.2004.04.004

[56] Pattanayak, S.K., Mercer, D.E., Sills, E. and Yang, J.-C. (2003) Taking Stock of Agroforestry Adoption Studies. Agroforestry Systems, 57, 173-186. https://doi.org/10.1023/A:1024809108210

[57] Caviglia-Harris, J.L. (2003) Sustainable Agricultural Practices in Rondonia, Brazil: Do Local Farmer Organizations Affect Adoption Rates? Economic Development and Cultural Change, 52, 23-49. 